\title{
Discussion on Death and Dying
}

Since moving into lecturing, I have become interested in discussions around death and dying, this is not something that I had been directly involved in during my career as a behaviour nurse specialist. Last year I had the opportunity to spend some time with Tracey LLoydd, Wales first Learning Disability Macmillan nurse and at a conference she organised, I was able to hear Lecturer, Stuart Todd talking about his work on where people with learning disabilities are when they die and who they are with, this inspired me to further reflect on the discussions we have in class with preregistration student nurses around death and dying.

Death and dying is part of the curriculum, we discuss lifespan care and needs of the aging population, health inequalities, co-morbidities and communication among other key factors in meeting the needs of people with learning disabilities. Cavaye and Watts (2014) reflected in their review that the curricula has been criticised for the limited focus on death and dying, however acknowledge that there are emerging attempts to embed and develop this within programmes. Strengthening the commitment (2012) describes the need for learning disability nurses to be prepared to meet the needs of an increasingly complex population and it would seem that specific preparation in discussing death and dying is essential in relation to this.

I recently attended a breaking bad news conference at St Georges hospital hosted by Irene Tuffrey-Wijne. The workshop was made up of people with learning disabilities, family members, carers and other professionals who shared and reflected on their experiences of death and dying, specific links were made to cancer and people with learning disabilities experiences. Amanda Cresswell, told her story as a lady with a learning disability reflecting on how she felt when her mum died without having been involved at all in any preparations and then later her own experience of having cancer. The feeling of being excluded and unprepared in the death of her mother and not being listened to in healthcare situations came through her discussion. She reflected that she had knowledge and understanding because at the time she delivered training to doctors on how to communicate with people with learning disabilities, but still felt disempowered in the early stages of her diagnosis and treatment. This reflects that while there are some people with learning disabilities who are equipped to deal with the issues the professionals and services around them may not be. Indeed common points raised when reflecting on why people aren't involved in these discussions are often around a perceived need to protect the individual or that they won't be able to cope with or understand the information presented to them. 
Amanda sat on a panel with two other people with learning disabilities who had different experiences and perceptions of the important communication points and meeting the needs of people with learning disabilities with sensitive and difficult information. All agreed that the person diagnosed with a life limiting condition had the right to know, the importance of making this understandable was emphasised. They discussed the words that can be used to tell people with learning disabilities that someone had died, gone, was in a better place, was resting in peace or had passed away etc. The books beyond words are a great resource to support these difficult conversations and excerpts were used throughout the workshop to structure the discussions that we had around a case study 'John is dying'.

Some challenges were brought up throughout the day with regard to when a good point to start having these difficult conversations could be and what to do when people do not want to discuss death (as is their right, as is mine and yours). Overall it seems that the issues in discussing death and dying relate to our own reluctance to face our mortality and discuss death/dying, if this is a difficult concept for us as adults and professionals how can we ensure that we give meaningful opportunities to those individuals with learning disabilities who may be grieving, bereaved, ill or dying?

It is obvious that we all experience bad news, illness and death in our own unique way as human beings and some people choose to live their lives without thinking ahead while others plan and prepare for the eventuality. Part of our role as nurses is to advocate for those with learning disabilities and provide information to them in a way that they can understand and make their own decisions as to how far they want to engage with the death and dying process. This is clearly a huge topic and some professionals reflect that they do not have the skills or the words to tackle emotive and sensitive topics such as this. I left the conference wondering is there a role for a learning disability specific death café, where conversations can be started in a safe and unstructured way, gathering information about the needs of individuals and developed further? I have started discussions with some of the placement areas I cover and hope this will be a project we can take forward in the North East, this approach may support nurses to develop their confidence in discussing a sensitive and challenging issue.

Cavaye, J. and Watts, J. H. (2014) An Integrated Literature Review of Death Education in Pre-Registration Nursing Curricula: Key Themes, International Journal of Palliative Care, vol. 2014,

Cresswell, A. \& Tuffrey-wijne, I. (2008) The comeback kid: I had cancer, but I got through it. British Journal of Learning Disabilities 36:13 pp.152156 
Scottish Government (2012) Strengthening the Commitment: The report of the UK Modernising Learning Disabilities Nursing Review. Scottish Government, Edinburgh.

www.booksbeyondwords.co.uk 